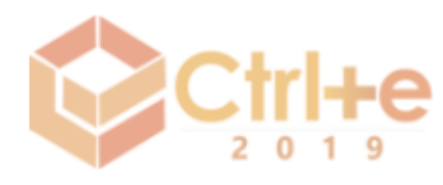

\title{
O Uso de Dispositivos Móveis para o Tratamento da Informação: Uma Revisão Sistemática de Literatura
}

\author{
Elvis Medeiros de Melo, Dennys Leite Maia \\ Instituto Metrópole Digital - Universidade Federal do Rio Grande do Norte (UFRN) \\ Av. Sen. Salgado Filho, 3000 - Lagoa Nova, CEP: 59.078-970 - Natal - RN - Brasil \\ elvismedeiros.mmegmail.com, dennyseimd.ufrn.br
}

\begin{abstract}
Through a Systematic Review of Literature (RSL) in proceedings of congresses in the area of Educational Technology, this research aimed to identify articles dated 2014 to 2017 that deal with the use of mobile devices for the Treatment of Information (TI). The results show that, despite recent research involving practices with mobile devices for Information Processing, there is an increase in production in recent years, in addition, there were no searches that made use of applications for smartphones for TI.
\end{abstract}

Resumo. Por meio de Revisão Sistemática de Literatura (RSL) realizada em anais de congressos na área de Tecnologia Educacional, a presente pesquisa teve como propósito identificar artigos de 2014 a 2017 que versassem sobre o uso de dispositivos móveis para o Tratamento da Informação (TI). Os resultados mostram que, apesar de recentes as pesquisas envolvendo práticas com dispositivos móveis para o Tratamento da Informação, há um aumento na produção nos últimos anos, além disso, não houve pesquisas que fizessem o uso de aplicativos para smartphones para TI.

\section{Introdução}

As práticas sociais com o Tratamento da Informação1 (TI) podem ser proporcionadas por diversos meios tecnológicos, como os dispositivos móveis. Contudo, mais do que um preconceito, os professores parecem ter dificuldades sobre como integrar essas ferramentas em sala de aula. De acordo com o Comitê Gestor da Internet no Brasil (CGI.BR), 39\% dos professores afirmam nunca ter utilizado dispositivos móveis em atividades com alunos e 15\% utilizaram menos de uma vez por mês [CGI.Br 2017]. Portanto, menos da metade dos professores exploram o potencial dessa ferramenta. $\mathrm{O}$ uso de apps educativos é uma das possibilidades. Não basta ter acesso à tecnologia e usar sem propósito pedagógico claro. O professor deve ter em mente que essa ferramenta abre oportunidades, e se bem aproveitada é de grande importância para o crescimento e avanço de seu conhecimento [Lévy 1999].

A mobilidade trazida pelo uso dos dispositivos móveis proporcionada pelos apps educativos salta aos olhos dos professores que precisam repensar a metodologia referente ao uso de recursos educacionais e digitais. A simples replicação de situações tradicionais de uso de quadro e giz, convertidos para uso de projetor multimídia, bem como a exploração descontextualizada de editores de textos, planilhas eletrônicas, softwares educativos e demais recursos da internet, não proporcionam reais modificações no seu 
fazer pedagógico nem tampouco impactam nos resultados do processo de aprendizagem. Para Moran (2010), isso é apenas aplicar um "verniz de modernidade" às aulas, sem alterar o cerne da questão, que é a metodologia.

É importante enfatizar também que, para uma aprendizagem significativa, faz-se necessário traçar os objetivos específicos para o uso destes equipamentos, uma vez que, ao serem utilizadas de forma planejada e mediada, as tecnologias móveis podem se tornar importantes aliadas nos processos de ensino e de aprendizagem. As peculiaridades desses dispositivos, cada vez mais equipados, contando com recursos como câmeras (que fotografam e filmam com boa qualidade de som e imagem), gravadores de áudio, calendários, comunicadores instantâneos, calculadoras e tantas outras ferramentas, possibilitam a criação de projetos e ações pedagógicas que não podem e nem devem ser desprezadas [Machado 2010].

Segundo Borba (2010), de modo geral, utilizar tecnologias informáticas, em um ambiente de ensino e aprendizagem, requer a sensibilidade do professor ou pesquisador para optar por estratégias pedagógicas que permitam explorar as potencialidades desses recursos, tornando-os didáticos. Ainda vale o alerta que Valente (1998) fez há mais de vinte anos: o educador deve conhecer o que cada uma destas facilidades tecnológicas tem a oferecer e como podem ser exploradas em diferentes situações educacionais. Apesar de todas essas evidências e indicações, e de novas tecnologias lançadas constantemente e que demanda apropriação, os professores ainda têm dificuldades de integrar as Tecnologias Digitais de Informação e Comunicação (TDIC) em suas práticas, relacionando-as com o objeto de conhecimento de suas disciplinas.

Nesse âmbito, voltando nosso olhar para o Tratamento da Informação, pesquisas como Ainley, Nardi e Pratt (2000); Magina e Santos (2008) e Castro et al (2011) revelam que o estudo de gráficos com auxílio do ambiente computacional contribui para a aprendizagem de conceitos estatísticos. Conforme essas pesquisas, as TDIC, na maioria das vezes, auxiliam na visualização e exploração de um conjunto de atividades, propiciando novas formas de pensar e agir matematicamente. Para Castro e Castro-Filho (2012), atividades com TI mostram ser um ambiente promissor de produção de conteúdo, viabilizando a liberdade produtiva das crianças e evolução dor para o desenvolvimento da interdisciplinaridade e da capacidade argumentativa. De acordo com os dados da pesquisa, a experiência de uso das TDIC para a aprendizagem do TI ampliou os procedimentos e estratégias de coleta, organização de dados e comunicação, além de desenvolver o senso crítico, a autonomia, a criatividade e a leitura, o que favoreceu a análise e a interpretação de textos, imagens e gráficos.

Diretrizes para a Educação Matemática [Brasil 1997] defendem seu ensino por meio do desenvolvimento integrado dos conhecimentos. Para Cazorla (2012), diversos indivíduos afirmam possuir aversão a essa disciplina e, para a maioria, isso acontece por lembranças de aprendizagens escolares. Uma possível explicação para isso se deve à falta de percepção das possíveis aplicações sobre o conhecimento estudado, bem como sua utilidade para a vida desses indivíduos. Assim, constata-se a necessidade de um trabalho mais efetivo com os gráficos, relacionando o Tratamento da Informação, o conhecimento diário e a Matemática, além de outros conhecimentos curriculares como Ciências, Língua Portuguesa, Geografia, História, dentre outros [Castro e Castro-Filho 2012]. Observando o atual cenário brasileiro acerca de práticas a respeito do uso desses dispositivos móveis no ensino do Tratamento da Informação, identificamos a necessidade de uma Revisão 
Sistemática de Literatura (RSL) [Kitchenham 2004] que identifiquem estudos que versem sobre o panorama do uso dessas ferramentas2.

Este artigo estrutura-se na presente introdução; seguido do percurso metodológico utilizado na elaboração da RSL, incluindo a apresentação das perguntas da RSL; seção de resultados, na qual discorremos sobre os trabalhos selecionados e extração dos dados; considerações sobre a RSL; e referências consultadas. Com vista à problematização do tema, propomos a seguir os passos metodológicos da revisão de literatura.

\section{Percurso Metodológico da Revisão Sistemática de Literatura}

A Revisão Sistemática da Literatura (RSL) é um tipo de investigação focada em questão bem definida, que visa identificar, selecionar, avaliar e sintetizar as evidências relevantes disponíveis [Galvão e Pereira 2014]. Identificada a necessidade de RSL, segundo Kitchenham (2004), os próximos passos são: a criação de um protocolo da revisão, a seleção dos estudos primários, avaliar a qualidade dos estudos disponíveis e a extração e síntese dos dados. A criação de protocolo de revisão torna o processo de revisão mais confiável e passível de reprodutibilidade.

$\mathrm{Na}$ fase exploratória, propomos um levantamento bibliográfico, procurando por artigos científicos datados no período de 2014 a 2017 utilizando, para a busca, palavraschave referentes ao trabalho, como: Tratamento da Informação; Estatística; Statistics; Objetos de Aprendizagem; Learning Objets; Apps para Matemática; Dispositivos Móveis; Mobile devices. Buscamos artigos em revistas científicas na área de Informática Educacional, quais foram: Revista Tecnologias na Educação (TecEdu) e Revista Brasileira de Informática na educação (RBIE). Além de busca de artigos em revistas científicas na área de Informática Educacional, buscaremos em anais de eventos, quais sejam: Workshops do Congresso Brasileiro de Informática na Educação (CBIE); Workshop sobre Tecnologias Móveis na Educação (WTME); Simpósio Brasileiro de Informática na Educação (SBIE); Congresso sobre Tecnologias na Educação (Ctrl+E); Mostra de Práticas em Informática Educacional (MPIE); Workshop Informática na Escola (WIE). Serão avaliados de acordo com os critérios de inclusão, exclusão e de qualidade estabelecidos durante o levantamento [Kitchenham 2004].

Em uma análise inicial, a partir do primeiro filtro, foram analisados: primeiro se o título está de acordo com as principais palavras-chave do trabalho (Dispositivos Móveis, Tratamento da Informação/Estatística, Objetos de Aprendizagem); depois foi realizada a leitura do resumo. Neste processo, classificamos os artigos como fortes, médios e fracos. Esses critérios estão de acordo com a proposta de Wazlawick (2014). Em análise inicial dos artigos, procuramos respostas para os seguintes questionamentos:

- Q1. Como estão sendo utilizados os dispositivos móveis nas pesquisas selecionadas?

- Q2. Qual dispositivo móvel é mais citado nas pesquisas?

- Q3. Em quais níveis de ensino estão sendo empregadas práticas com dispositivos móveis para o Tratamento da Informação?

Essas perguntas serviram como referência para definirmos categorias de análise deste trabalho. No levantamento do estado da arte da pesquisa, na primeira fase foram encontrados 115 artigos, analisando apenas pelos títulos. Dentre as plataformas consultadas, segue o quantitativo de trabalhos encontrados:

2 A presente pesquisa está inserida no âmbito do projeto "Desenvolvimento Profissional de Professores que Ensinam Estatística" (D-ESTAT), desenvolvida no decorrer do ano de 2019 para dissertação de mestrado do primeiro autor. 
Gráfico 1. Quantidade de artigos de acordo com a base de pesquisa selecionada

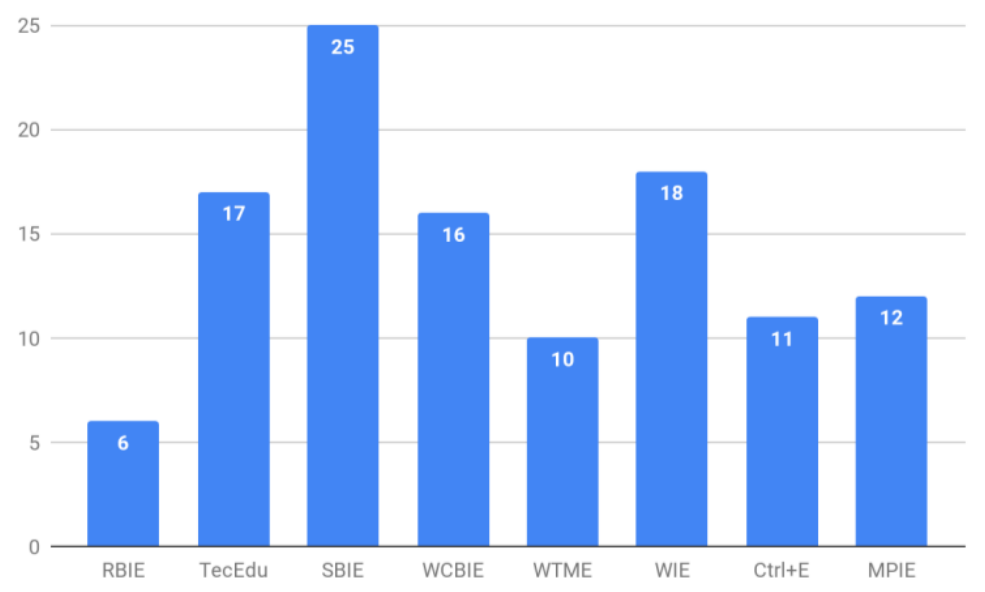

$\mathrm{Na}$ fase de revisão de literatura, foram catalogados 115 artigos encontrados de acordo com parâmetros estabelecidos na metodologia. Consideramos 44 fortes, 29 médios e 42 fracos para a construção do estado da arte sobre práticas em TI com dispositivos móveis. Os 44 artigos considerados fortes foram lidos e fichados. O Gráfico 2 mostra a quantidade de artigos por meio digital consultado.

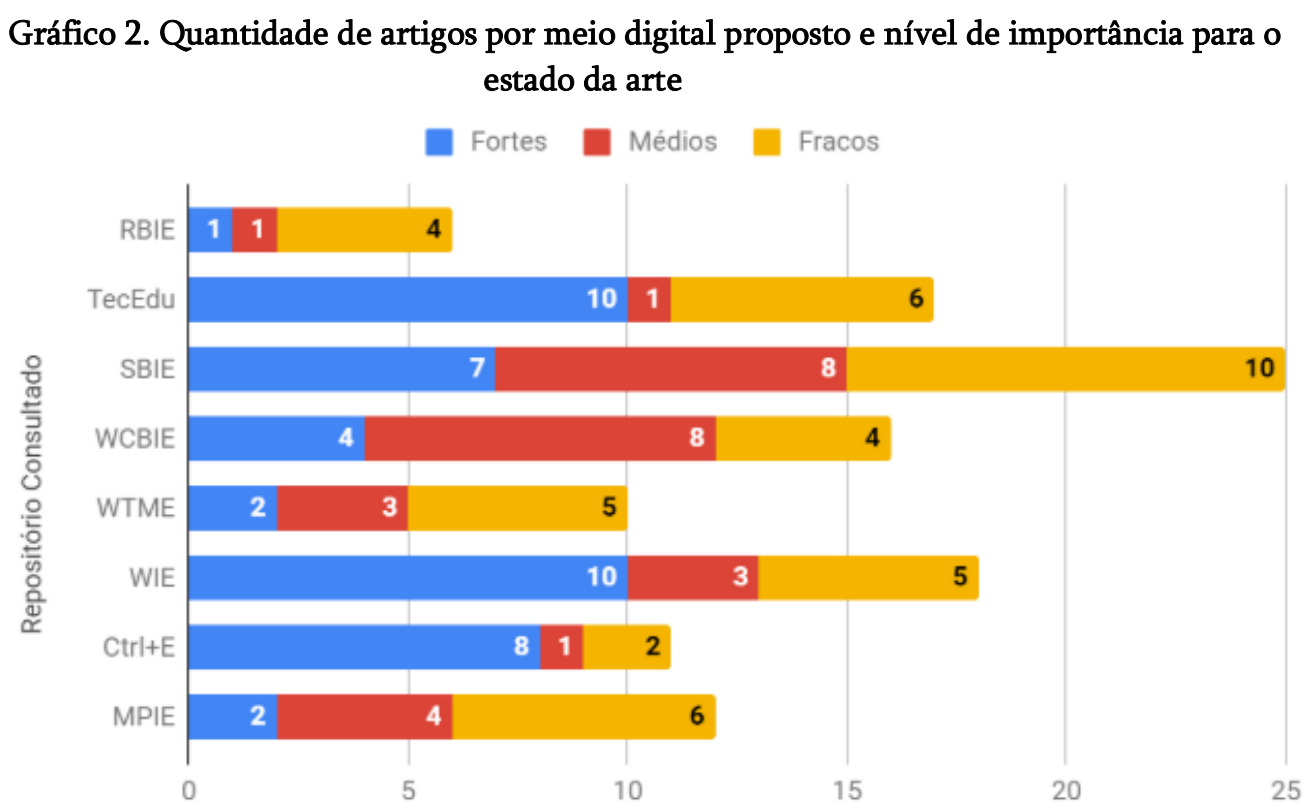

Citamos os artigos considerados fortes dos repositórios consultados de maneira sistemática nesta RSL. Assim, com bases nos procedimentos expostos, a seguir, apresentamos nossas percepções sobre a produção acadêmica acerca do uso de dispositivos móveis para o Tratamento da Informação.

\section{Resultados e Discussões}

No processo de leitura e fichamento, observamos que, apesar de alguns artigos terem sido considerados fortes, eles não respondiam nenhuma das perguntas desta RSL. Para fins de qualidade na discussão, optamos por não citá-los. Nesse processo, artigos foram reclassificados para a categoria médios, sendo destes: 1 do SBIE; 4 do WIE; Nenhum do WTME; 2 do WCBIE; 5 do Ctrl+E; 1 da MPIE; 1 da RBIE e 7 da TecEdu. No total, foram desconsiderados 21 trabalhos, totalizando 23 fortes após segunda triagem. 
Após a análise e fichamento de todos 23 trabalhos fortes que respondiam a pelo menos uma das perguntas da RSL. Realizou-se a organização dos mesmo por ano de publicação com o objetivo de verificar qual o panorama e popularidade de pesquisas relacionado ao tema no período escolhido para análise. Observamos um crescimento da quantidade de produção no decorrer dos anos, com um decrescimento em 2017. Ao analisar as instituições das quais os autores são filiados, pudemos observar que a maior parte dos estudos sobre dispositivos móveis no âmbito escolhido está na região Sudeste (ver Figura 1), apesar de a instituição com mais publicações ser a Universidade Federal do Ceará (UFC), seguida da Universidade Federal do Amazonas (UFAM), portanto, das regiões Nordeste e Norte, respectivamente (ver Figura 2).

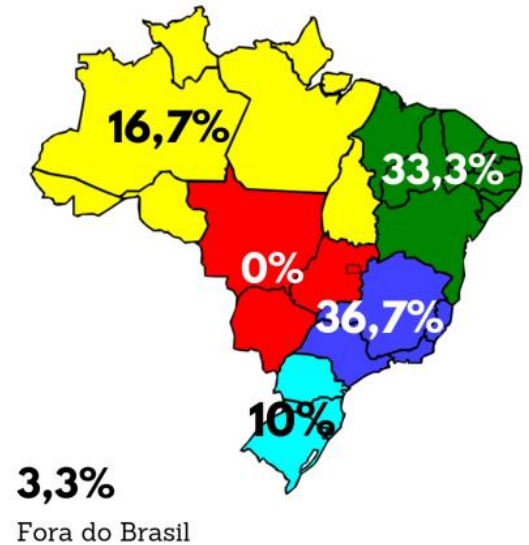

Figura 1. Instituições por Região

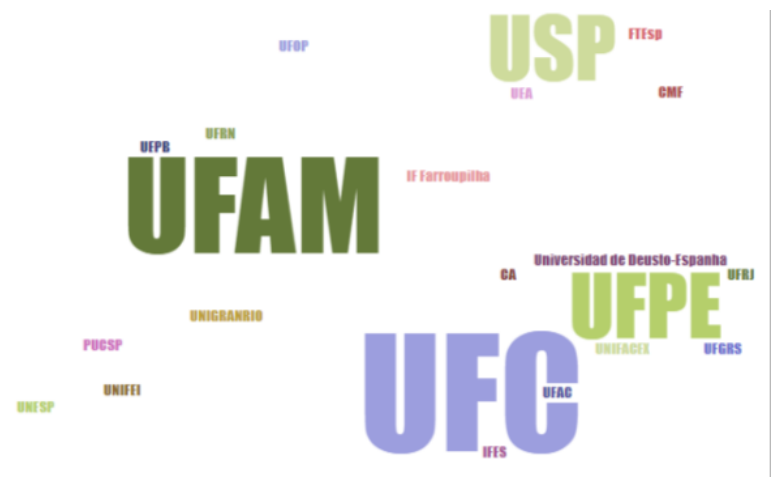

Figura 2. Instituições com mais publicações

Após a leitura dos artigos relevantes para esta pesquisa, percebeu-se que seus autores usaram, essencialmente, referências de estudos com a finalidade de conceituar os termos como: aprendizagem móvel (ou m-learning), uso de dispositivos móveis pelos estudantes (BYOD, por exemplo) e justificar uma teoria. A seguir, procuramos responder as perguntas delimitadas pela revisão sistemática de literatura segundo a análise dos artigos selecionados.

\subsection{Como estão sendo utilizados os dispositivos móveis nas pesquisas selecionadas?}

Pensando na aplicação desses dispositivos em experiências inovadoras para o Tratamento da Informação, Hitzschky et al (2016) relata o uso de tecnologias móveis em aulas em campo realizadas em uma escola pública de Aquiraz/CE, e que apresenta práticas educativas utilizadas com a inserção destes dispositivos na dinâmica escolar, bem como, as contribuições significativas que estas ferramentas ofereceram aos alunos e professores nos processos de ensino e de aprendizagem. Com a utilização dos dispositivos móveis (netbook e smartphone, neste caso) na rotina escolar, os alunos podem compreender a construção de conhecimentos com outro olhar e com uma visão mais participativa do processo e de quem o constrói. A partir do trabalho com esses recursos, a formação de alunos mais argumentadores, críticos e responsáveis pelas causas que também são deles, é amplamente possibilitada por meio de práticas e abordagens que fogem das metodologias tradicionalmente configuradas no ambiente formal de ensino que é a escola.

Já o trabalho de Lima, Lima-Neto e Castro-Filho (2015) traz o relato de experiência sobre o uso de dispositivos móveis para a realização de uma intervenção no âmbito escolar de uma escola pública de Educação Básica da região metropolitana de 
Fortaleza/CE. Ela foi direcionada como uma pesquisa de intervenção, em que o pesquisador intervém diretamente no ambiente natural dos pesquisados tendo como um de seus principais objetivos propor mudanças sociais. Contou com a participação de grupo de 10 alunos do $7^{\circ}$ ao $9^{\circ}$ Ano do Ensino Fundamental. Estes alunos exploraram diversos assuntos sobre sustentabilidade com o uso de dispositivos móveis (netbooks e smartphones) em atividades em grupo durante dois meses no contraturno da escola. Como resultados, os autores concluem que a mobilidade sociointeracional e temporal permitiu que o grupo aproveitasse a oportunidade para discutir de forma síncrona e assíncrona sobre o tema do projeto, não se limitando apenas aos momentos presenciais.

Em "Esquadrão Graphics: em repórter por um dia", Silva et al (2015) idealizaram um $\mathrm{OA}$ que se destinou às aulas de Matemática, mas com potencial intra $\mathrm{e}$ interdisciplinares proporcionadas pelos gráficos e produções textuais. Como público-alvo tiveram estudantes da Educação Básica com faixa etária entre 11 e 13 anos do $6^{\circ}$ e $7^{\circ}$ ano do Ensino Fundamental. Durante a pesquisa, revelou-se a preferência dos estudantes pelo gênero textual HQ (História em Quadrinhos). Como resultado, tem-se um recurso com características interdisciplinares por permitir a ligação do Tratamento da Informação, bloco pertencente à Matemática, de acordo com os PCN [Brasil 1997], com a Língua Portuguesa, por necessitar a compreensão das características do gênero textual notícia. Não foi realizada testagem do OA desenvolvido com os estudantes, apenas pesquisa com grupo focal. Em atividades com TI, é importante que o professor procure saber a preferência de temas com os estudantes, para que as práticas de construção de gráficos e análises estatísticas façam sentido em seu contexto. Foi organizado um material de enriquecimento em Vieira e Conforto (2015) com o objetivo de subsidiar a produção de textos argumentativos-dissertativos de estudantes do Ensino Médio. Atividades com TI devem estar integradas com as demais disciplinas da Educação Básica [Brasil 1997], assim como na produção de artigos científicos por estudantes para embasamento quantitativo de suas pesquisas [Melo e Maia 2018]. Os resultados da pesquisa de abordagem qualitativa reafirmaram os dispositivos móveis (neste caso, os autores utilizaram o smartphone) como símbolo identitário de adolescentes, evidenciaram suas vantagens quanto à ubiquidade, à pervasividade e sua inserção no cotidiano escolar, confirmando o potencial pedagógico de uma estratégia de m-learning na construção do pensamento argumentativo. A estratégia de m-learning apresentada deu visibilidade às possibilidades de desterritorializar a tecnologia, retirando a exclusividade do laboratório de informática como o espaço autorizado para o uso da linguagem digital, rompendo com a rigidez da delimitação espaço-temporal no gerenciamento do uso da tecnologia na escola, que tem sido mantida mesmo com a presença dos smartphones. A mobilidade proporcionada pelo uso dos smartphones, como ressalta Moran (2013), faz com que novas propostas de uso de smartphones em atividades de TI possam ser inseridas no contexto da escola e a ressignificar espaços anteriormente subutilizados, como o laboratório de informática, por exemplo.

Ao analisar estudos que levam em consideração o uso de smartphones e apropriação dessas tecnologias no ensino do Tratamento da Informação, Pereira et al (2016) apresentam possibilidades de uso de jogos digitais para a aprendizagem de conceitos matemáticos. com o auxílio das redes sociais (Facebook e WhatsApp) incluindo a perspectiva m-learning por meio do bring your own device (BYOD), ou seja, com os dispositivos móveis dos alunos. Parte do pressuposto de que os jovens constroem aprendizagens mediadas por jogos digitais nos anos finais do Ensino Fundamental, eles desenvolvem habilidades cognitivas, afetivas, sociais e culturais e apropriam-se de 
conhecimentos da matemática, entre eles os conhecimentos relacionados ao Tratamento da Informação. Em contrapartida, ao analisar a formação inicial para o trabalho com o TI na Educação Básica, Oliveira et al (2017) desenvolveram uma pesquisa-ação realizada com alunos de Licenciatura em Matemática, com o objetivo de avaliar a percepção e aptidão dos participantes quanto à utilização das TDIC em dispositivos móveis como recurso didático. $\mathrm{O}$ método foi dividido em três partes: diagnóstico inicial, oficina e avaliação final. A Oficina, ação da pesquisa constituiu-se de uma apresentação sobre os conceitos principais do m-learning; da exposição das funcionalidades e principais características de 6 aplicativos escolhidos dentre os listados no diagnóstico inicial e de atividades práticas com os participantes utilizando tais aplicativos. O critério para a escolha dos apps foi a maior porcentagem de participantes que conheciam os aplicativos, a disponibilidade dos mesmos para o sistema Android e ainda, uma avaliação geral dos apps pelos autores da pesquisa. Para a escolha dos aplicativos de apoio, além dos anteriores, utilizou-se o critério de que os apps não tivessem as mesmas funcionalidades.

Levando-se em consideração o TI como conteúdo interdisciplinar [Brasil 1997], Gaspar, Oliveira e Oliveira (2015) realizam uma RSL para identificar apps que trabalhem a m-learning para o ensino de Língua Portuguesa. Dentre os resultados, eles confirmaram a existência de poucas publicações relacionando a aprendizagem da Língua Portuguesa com dispositivos móveis. Poucos trabalhos propõem um novo aplicativo, ao mesmo tempo que poucos exploram devidamente as possibilidades inerentes aos aparelhos móveis (em especial smartphones e tablets), especialmente seu grande potencial de inovação. O ensino de TI integrado com outras áreas do conhecimento, como a Língua Portuguesa, traz mais significado devido a natureza de seus conteúdos [Castro e CastroFilho 2012] [Silva et al 2015] apesar de serem poucos os recursos desenvolvidos. Ao propor um levantamento de apps para um repositório de objetos de aprendizagem para Matemática, Melo, Costa e Maia (2017) catalogaram e classificaram 184 apps com potencialidade pedagógica. Em contrapartida, encontraram apenas 23 recursos desenvolvidos para a área do TI.

Viana Filho et al (2017) apresentam os resultados de uma experiência com alunos do nono ano regular (Ensino Fundamental), na disciplina de Matemática utilizando dispositivos móveis. Para mediar a experiência, fizeram uso do smartphone, como dispositivo móvel, e da rede social WhatsApp. Para o estudo da Matemática, utilizaram o app Geogebra para Android, com o objetivo de estudar os gráficos das funções polinomiais de primeiro e segundo graus. A partir dos diálogos estabelecidos durante a execução das tarefas e das considerações feitas pelos alunos, a experiência mostrou que os smartphones podem mediar o ensino de Matemática, cumprindo seu papel social e motivando a aprendizagem do aluno em seu cotidiano. A construção de gráficos por meio de apps tem sido uma atividade explorada em trabalhos acadêmicos na modalidade de relato de experiência, assim como o desenvolvimento de ferramentas para smartphone. A estratégia utilizada pelos autores encontrados nesta RSL é a pesquisa exploratória, com o intuito de mapear o que se tem desenvolvido e, com base nas suas necessidades, propõem e elaboram artefatos para o Tratamento da Informação. Observamos que, apesar de identificarmos pesquisas que utilizam dispositivos móveis em para o Tratamento da Informação, nenhuma das experiências fizeram uso de smartphones com uso de apps. Uma proposta de dissertação de mestrado está alinhada justamente a essa necessidade de uso e reflexão sobre a prática de Tratamento da Informação com smartphones dos estudantes sob a perspectiva BYOD. A seguir, vejamos os resultados das demais perguntas da RSL. 


\subsection{Qual dispositivo móvel é mais citado nas pesquisas?}

Responderemos essa pergunta por meio de uma compilação exibida no Gráfico 4.

Gráfico 4. Dispositivos móveis citados nas pesquisas

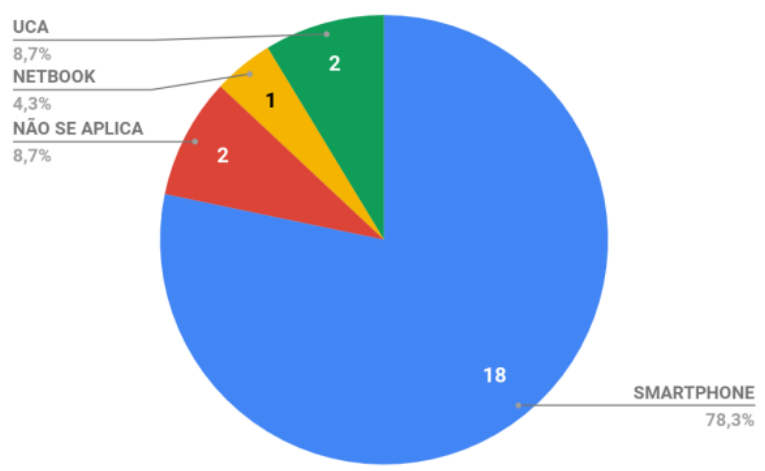

Aqui, observamos que uma grande maioria dos estudos utilizam o smartphone como dispositivo móvel protagonista em suas análises. Um fato a ser observado é que em todas essas pesquisas o sistema operacional deste dispositivo é o Android, nas suas diferentes versões, de acordo com o correr dos anos em que as pesquisas foram publicadas. Houve duas pesquisas que integraram o smartphone com o uso do laptop UCA (Um computador por aluno) oriundas da UFC. Além disso, houveram duas pesquisas cujo objetivo foi o desenvolvimento de softwares mais robustos para a aprendizagem do TI para computadores desktop, que não foi considerada nesta contagem.

\subsection{Em quais níveis de ensino estão sendo empregadas práticas com dispositivos} móveis?

O gráfico que responde à pergunta, com base na análise do contexto dos artigos, é apresentado a seguir. Nas pesquisas em que não citava uma série escolar específica, mas no contexto os autores citam a Educação Básica (desde a Educação Infantil até o Ensino Médio, segundo Lei $n^{\circ} 9.394$ de 20 de Dezembro de 1996 de Diretrizes e Bases da Educação Brasileira) acrescentamos essa categoria para enquadrar esses estudos.

Gráfico 5. Níveis de ensino das pesquisas selecionadas

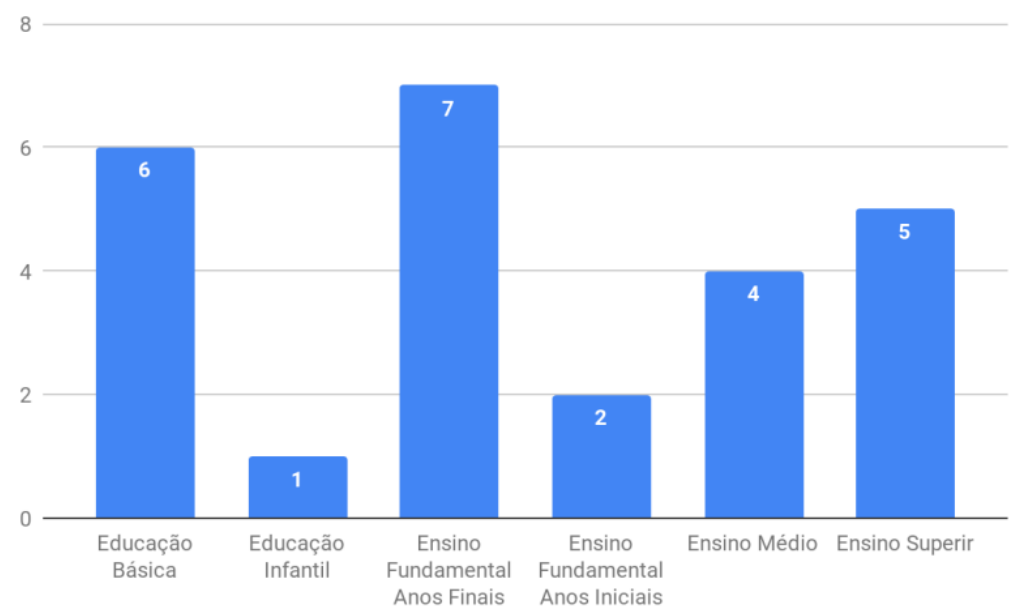

Observamos uma grande quantidade de pesquisas focadas nos anos finais do Ensino Fundamental, no Ensino Médio e na Educação Superior. É interessante notar também que esses indivíduos estão na categoria trazida pelo CGI.Br (2017), no qual o 
uso do smartphone foi citado por $52 \%$ dos alunos de escolas com turmas de $5^{\circ}$ e $9^{\circ}$ anos do Ensino Fundamental ou $2^{\circ}$ ano do Ensino Médio, localizadas em áreas urbanas [CGI.Br 2017].

\section{Considerações}

O uso de dispositivos móveis ainda é um tema que deve ser pesquisado para propiciar a quebra de paradigma e rever seu uso como um recurso viável a ser utilizado no espaço escolar, tendo em vista que os artigos analisados ressaltaram experiências com dispositivos móveis na sala de aula nunca utilizados nos locais onde as pesquisas foram desenvolvidas. Observamos o uso tímido no cenário das pesquisas levantadas através desta RSL e que, apesar de haver um aumento das pesquisas no decorrer dos anos, nenhuma fez o uso de apps para smartphones para o Tratamento da Informação. No geral, esta revisão de literatura ajudou a responder as perguntas delineadas na metodologia, além de suscitar novas questões sobre o uso dos dispositivos móveis para o ensino das habilidades relacionadas ao TI. Pretendemos expandir o estudo com análise de outros repositórios de congressos, aumentando o escopo para escrita de dissertação de mestrado e embasamento e busca dos questionamentos aqui levantados, dentro de outros contextos.

\section{Referências}

Ainley, J., Nardi, E.; Pratt, D. (2000). "Towards the construction of meaning for trend in Active Graphing, International Journal of Computers for Mathematical Learning”; 5.2, p. 85-114.

Borba, M. de C.; Lacerda, H. D. G. (2015). "Políticas públicas e tecnologias digitais: um celular por aluno". Educação Matemática Pesquisa (EMP), São Paulo, v.17, n.3, p.490-507.

Borba, M.C. (2010) "Softwares e internet na Sala de Aula", In: X ENEM - Encontro Nacional de Educação Matemática, Brasil.

Brasil (1997). Secretaria de Educação Fundamental. Parâmetros curriculares nacionais: matemática /Secretaria de Educação Fundamental. - Brasília: MEC/SEF, 142p.

Castro, J.; Castro-Filho, J. A. (2012) Projeto Um Mundo de Informações: integração de tecnologias digitais ao currículo escolar. In: Anais dos Workshops do CBIE 2012.

Castro et al (2011). Objetos de Aprendizagem digitais como suporte para a construção e compreensão de gráficos. In: Anais da XIII CIEAEM. Recife: Edumatec/UFPE.

Cazorla, I. M. (2012) "Metodologia do ensino da matemática". 3. Ed. Bahia: Editus Editora.

CGI.BR. (2017) "Pesquisa sobre o uso das tecnologias de informação e comunicação nas escolas brasileiras: TIC educação 2016". São Paulo: Comitê Gestor da Internet no Brasil.

Galvão, T.F.; Pereira, M.G. (2014). "Revisões sistemáticas da literatura: passos para sua elaboração". In: Epidemiol. Serv. Saúde: v.23, n.1. Brasília: março, 2014.

Gaspar, W.; Oliveira, E.; Oliveira, K. (2015) Aprendizagem da Língua Portuguesa com Dispositivos Móveis: Um Mapeamento Sistemático da Literatura. In: Simpósio Brasileiro de Informática na Educação - SBIE. Anais do SBIE 2015.

Hitzschky, R. A. et al. (2016) Práticas Educativas Com O Uso De Dispositivos Móveis Em Aulas De Campo: Aprendizagem Para Além Dos Muros Da Escola. In: Congresso Regional sobre Tecnologias na Educação, 2016, Natal. Anais do Congresso Regional sobre Tecnologias na Educação, 2016. p. 210-219.

Kitchenham, B. (2004) "Procedures for performing systematic reviews". Keele, UK, Keele University, v. 33, n. 2004, p. 1-26, 2004.

Lévy, P. (1999). Cibercultura. São Paulo: Ed. 34.

Lima, M. S. S.; Lima, L. L. V.; Lima-Neto, C. S.; Castro-Filho, J. A. (2016). Experiência de Aprendizagem Móvel: o uso do WhatsApp no Ensino Fundamental. In: V Congresso Brasileiro de Informática na Educação (CBIE 2016). Anais dos Workshops do V Congresso Brasileiro de Informática na Educação (WCBIE 2016).

Machado, J. L. A. (2010) Celular na sala de aula: O que fazer?. Disponível em: $<$ https://goo.gl/EGtSNx>. Acesso em: 15 mar. 2019. 
Magina, S. M. P; Santos, S. S. (2008) Estratégias de Interpretação Gráfica de uma Professora Polivalente ao Manipular Dados no Ambiente Computacional. Revista Bolema, Rio Claro (SP), Ano 21, n 29, 2008, pp. 157 a 174.

Melo, E. M.; Costa, C. J. N.; Maia, D. L. Recursos educativos digitais para Educação Matemática: um levantamento para dispositivos móveis. In: Congresso sobre Tecnologias na Educação (Ctrl+E), 2017, Mamanguape/PB. Anais do Ctrl+E 2017, p.448-459.

Melo, E.M.; Maia, D.L. (2018) Metodologias Ativas em Estatística: relato de experiência em práticas com tratamento da informação. In: Com a Palavra o Professor, Vitória da Conquista (BA), v.3, n. 2, maio-agosto.

Moran, J. M. (2010) "Os novos espaços de atuação do educador para a inovação". Inovação na Educação. In: Revista Aprendizagem, Paraná, IFPB, v.2 n.17, p. 62-63, março/abril.

Moran, J. M. (2013). A educação que desejamos. Novos desafios e como chegar lá. Campinas: Papirus.

Moran, J. M. (2015) Mudando a educação com metodologias ativas. In: Souza, C. A. De; Morales, O. E. T. (Orgs.). Convergências midiáticas, educação e cidadania: aproximações jovens. Ponta Grossa, PR: Foca Foto-PROEX/UEPG, p.15-33.

Oliveira, R. C. et al (2016). Aplicativo de Aprendizagem Móvel utilizando Realidade Aumentada para Ensino de Língua Inglesa. In: V Congresso Brasileiro de Informática na Educação (CBIE 2016). Anais dos Workshops do V Congresso Brasileiro de Informática na Educação (WCBIE 2016).

Ribeiro, P. M. S. (2015) Aplicativo Para Ensino De Estatística: Uma Avaliação No Seu Uso. Disponível em: <https://goo.gl/w6VtuV>. Acesso em: 13 mar. 2019.

Pereira, A. B. C.; Silva, F. S. C.; Piconez, S, C. B; Zimmer J. M. (2016). Jogos digitais no desenvolvimento de conceitos matemáticos sob perspectiva BYOD e abordagem m-learning na escola pública. In: V Congresso Brasileiro de Informática na Educação (CBIE 2016). Anais do XXII Workshop (WIE 2016).

Silva, L. et al (2015) Esquadrão Graphics: em repórter por um dia. In: Congresso Brasileiro de Informática na Educação (CBIE 2015): Workshops do IV Congresso Brasileiro de Informática na Educação (CBIE 2015).

Valente, J. A. (1998) "Diferentes usos do computador na educação". In: Diferentes usos do computador na educação. $\mathrm{O}$ uso inteligente do computador na educação.

Viana Filho, J.P. et al (2017) Aprendizagem Móvel: uma experiência com alunos de nono ano na disciplina de Matemática. Disponível em: $<$ https://goo.gl/x1yeD3>. Acesso em: 13 de mar. 2019.

Vieira, M, C; Conforto, D. (2015). Aprendizagem móvel e multimídia: a produção de material pedagógico na perspectiva BYOD. In: CBIE-LACLO 2015. Anais do XXI Workshop (WIE 2015).

Wazlawick, R. S. (2014) Metodologia de pesquisa para ciência da computação. 2.ed. Rio de Janeiro: Elsevier. 